\title{
A LUTA DIÁRIA DOS MOTOTAXISTAS EM CAMPINA GRANDE-PB
}

\author{
Anny Glayni Veiga Timóteo ${ }^{1}$
}

\section{Introdução}

Com o decorrer dos anos, os meios de transportes passaram por várias mudanças. Aqueles que eram utilizados apenas para passeio, ou mesmo como meio de locomoção, passam a ser o meio de trabalho de alguns proprietários ou até mesmo a servir como forma de diversão. Um exemplo que se adapta a essa mudança são as motocicletas. Estas obtiveram um novo "papel” no cenário do trânsito brasileiro. Com a facilidade que a mesma ostenta em driblar o trânsito parado, conseguindo chegar rapidamente nos lugares desejados, passam ser uma ferramenta de trabalho, foi em decorrência dessa agilidade que os motoboys, por exemplo, ingressam nesse tipo de trabalho. Sua função caracteriza-se na entrega de algumas encomendas, como comida e medicamentos, e apresenta como meta principal conseguir realizar suas entregas em tempo recorde, existindo estabelecimentos que estipulam um tempo máximo de entrega, independente da distância, fazendo com que os motoqueiros avancem sinal, ultrapassem de maneira perigosa e inadequada para que a entrega chegue ao determinado local com maior rapidez. Podemos encontrar esta realidade retratada no documentário "Motoboys - Vida Louca" dirigido por Caíto Ortiz, no qual pode-se perceber um pouco da vida desses motoboys em São Paulo. Retratando o dia-a-dia de um pequeno grupo de motoboys, Caíto Ortiz consegue abordar os diferentes motivos que fez com que essas pessoas ingressassem neste meio.

Outra forma de utilizar a motocicleta como trabalho, são os mototaxistas. ${ }^{2}$ Estes vêm ganhando espaço em várias cidades. Em comunidades do Rio de Janeiro ${ }^{3}$, por exemplo, esse meio de transporte tornou-se importante para a locomoção dos moradores

\footnotetext{
${ }^{1}$ Universidade Federal da Paraíba, Brasil.

${ }^{2}$ Este texto diz respeito ao trabalho de campo que ocorreu entre 05 de maio e 06 de junho do ano de 2013 na região do Centro da cidade de Campina Grande- PB.

${ }^{3}$ Natasha Ramos da Fonseca realizou um trabalho na comunidade da Rocinha, Rio de Janeiro, intitulado: Sobre duas rodas: o mototáxi como uma invenção de mercado.
} 
nas ruelas que não apresentam estrutura para a passagem de um automóvel. Esta profissão na comunidade é bem reconhecida entre os jovens que possuem baixa escolaridade e não conseguem ingressar em outros meios de trabalhos, já que para ser mototaxista neste caso, necessita apenas possuir o veículo, e cadastra-se em um ponto da comunidade. O que aumenta o interesse dos jovens por esse trabalho é a liberdade que os mesmo possuem, já que não possuem patrão.

Na cidade de Campina Grande- PB, essa modalidade de emprego vem crescendo com o passar dos anos. ${ }^{4}$ Inicialmente, para realizar o trabalho, necessitava ter o veículo e ir à procura de passageiros. $\mathrm{O}$ reconhecimento desses trabalhadores passou a existir a partir da CG Moto-Táxi, uma empresa privada, que fornece esse serviço para os moradores de Campina Grande. Vale ressaltar que com o sucesso e o reconhecimento dessa empresa de Moto-Táxi houve o surgimento de outra empresa nos mesmos moldes, esta denominada Central Motos, que surgiu a partir de iniciativa do ex-presidente do Sindicato dos mototaxitas de Campina Grande, o SINDMOTO-CG, a qual possui respaldo legal visto ser sindicalizada e possuir incentivo por parte da Prefeitura para a organização e legalização dessa categoria. Surgindo a partir dessa nova organização de classe, a distinção entre os mototaxistas cadastrados - os legais e os nãos cadastrados os ilegais. Apesar dessa distinção entre mototaxistas legalizados e os não legalizados, o cerne deste estudo serão os mototaxistas que encontram-se cadastrados na STTP (Superintendência de Trânsito e Transportes Públicos), já que os mesmos estão alocados no centro da cidade, facilitando uma observação direta. Com este cenário, surge o anseio de mostrar como se dão as relações desses trabalhadores no âmbito urbano de Campina Grande, como eles são vistos e reconhecidos nesse meio.

\section{Caracterização desse meio de trabalho em Campina Grande}

Atualmente, com a dificuldade de oportunidade de trabalho, o que podemos notar é o crescimento dos trabalhos autônomos. O mototaxista, de certa maneira, se enquadra nesta perspectiva. Sendo estes encontrados em vários municípios. A cidade de Campina Grande é um espaço que também se utiliza deste serviço, fazendo-se interessante

\footnotetext{
${ }^{4}$ De acordo com Jucelino Pereira Luna, mototaxistas cadastrados "[...] existem atualmente 727 mototaxistas. Esses possuem permissão para circular na cidade como veículo habilitado para o transporte de passageiros, desde que estejam em dia com o Órgão Público responsável (STTP)." (LUNA, 2010: 107).
} 
analisar como se dão essas relações no meio urbano, nesse caso, na cidade de Campina Grande. De acordo com Robert Ezra Park:

A cidade, e especialmente a grande cidade, onde mais do que em qualquer outro lugar as relações humanas tendem a ser impessoais e racionais, definidas em termos de interesse e em termos de dinheiro, é num sentido bem real um laboratório para a investigação do comportamento coletivo. (Park, 1973: 45)

Percorrendo as ruas de Campina Grande, é possível nos depararmos com várias motocicletas paradas em locais específicos e alguns motoqueiros a procura de passageiros. Estes trabalhadores podem estar entre os que são cadastrados pela CG Moto-táxi, uma pequena empresa (a primeira da cidade), que surgiu por volta de 1996, no período em que não havia regulamentação: para fazer parte, o motoqueiro se cadastrava e a mesma disponibilizava um colete para os motoqueiros, que para ingressar neste trabalho, precisam ter sua própria motocicleta, apresentar habilitação e comprovar "ficha limpa" na Polícia Federal, Polícia Civil e do Tribunal de Justiça da Paraíba. Neste caso em particular, os motoqueiros ficam "alojados" em pontos distribuídos por alguns bairros da cidade ${ }^{5}$, aguardando a ligação da central de atendimento, que dependendo do local que o passageiro esteja, escolhe um mototaxista mais próximo do mesmo. Esses "alojamentos", normalmente caracterizam-se por serem em casas alugadas, galpões.

Outro tipo de mototaxista são aqueles cadastrados na prefeitura, que passam pelas mesmas exigências que os mototaxistas da CG Moto-táxi, diferenciando-se no ponto de apoio, já que estes apresentam vários pontos no centro e em outros bairros da cidade onde um principal é o da Praça da Bandeira, que se encontra no centro já que apresenta um número maior de mototaxistas e a forma como eles conseguem seus passageiros não demonstra uma ordem com relação a quem "pega a corrida primeiro", cada um "vai à procura do seu", dessa forma, eles ficam abordando seus passageiros de forma mais incisiva, perguntando a todos os pedestres que passam próximo ao ponto se precisam de moto, assim, é normal passar pela Praça da Bandeira e ouvir: "Moto? Moto? Vai uma moto ai?".

\footnotetext{
${ }^{5}$ Alguns ficam parados em outros pontos da cidade a procura de mais clientes.

${ }^{6}$ Expressão utilizada pelos mototaxistas com relação a quem consegue um cliente primeiro.
} 
Ainda neste cenário, podemos encontrar os mototaxistas "clandestinos", aqueles que não possuem nenhum cadastro, e podem alocar-se em vários locais da cidade. Normalmente, eles são encontrados em algumas ruas do centro da cidade ${ }^{7}$, onde se pode encontrar um fluxo maior de pessoas, possíveis passageiros, em alguns bairros da cidade. A caracterização dos mototaxistas clandestinos pode ser notada na fluidez que os mesmos possuem com relação aos espaços que eles podem assumir neste meio de trabalho. Hannerz (1997a) ao tratar da questão de fluxos, elucida que:

O termo já se tornou transdisciplinar, um modo de fazer referências a coisas que não permanecem no seu lugar, a mobilidade e expansões variadas, à globalização em muitas dimensões. Scott Lash e John Urry (1994: 4,12), teóricos sociais, dizem que as sociedades deste final de século se caracterizam por fluxos de capital, trabalho, mercadorias, informações e imagens. [...] (Hannerz, 1997: 10)

Com este cenário, podemos notar a pluralidade encontrada neste tipo de trabalho, algo muito comum nas populações urbanas, como já percebeu Park "a multiplicidade de ocupações e profissões dentro dos limites da população urbana é um dos mais notáveis e menos entendidos aspectos da vida citadina moderna" (Park, 1973: 27). Relacionando a forma como estes mototaxistas estão inseridos em seu meio de trabalho, além desses fluxos, podemos notar a presença de limites, de acordo com Hannerz: "se "fluxo" sugere uma espécie de continuidade e passagem, "limites", têm a ver com descontinuidades e obstáculos. Entendo por limite uma linha clara de demarcação, em relação à qual uma coisa ou está dentro ou está fora". (Hannerz, 1997: 15). Estas "linhas de demarcação" podem ser encontradas nos pontos em que os mototaxistas estão inseridos, por exemplo, os que são clandestinos, não param no local destinado aos mototaxistas cadastrados na STTP.

Estando neste ambiente urbano heterogêneo, onde as relações entre os motoqueiros aparecem em um misto de "cumplicidade" e concorrência, podemos encontrar esta cumplicidade entre os mototaxistas, quando acontece um acidente, por exemplo, ou quando algum condutor critica alguma manobra dos mototaxistas, de forma rápida e em conjunto, eles se unem para dar apoio ao seu "colega de trabalho". Mas, ao mesmo tempo em que existe esta cumplicidade, a concorrência é presente quando se

\footnotetext{
${ }^{7}$ Como não apresentam pontos fixos, normalmente eles param suas motos na Zona Azul, local destinado para estacionamento de motos, precisando pagar um valor para estacionar.
} 
trata de conseguir um passageiro. Os pontos ${ }^{8}$ onde podemos encontrar os mototaxistas demonstra a ansiedade por parte deles em conseguir um passageiro. Como o número de pessoas interessadas em pegar um moto-táxi é inferior em relação à quantidade de moto que se encontra parada, qualquer possível passageiro faz a diferença no trabalho deles, já que eles recebem por corrida realizada.

\section{Os "entraves" no contato com os mototaxistas: a questão da etnografia}

Falar de antropologia é remeter ao que chamamos de pesquisa de campo, utilizando o método etnográfico, "onde no saber convencional da disciplina, a etnografia desempenha um papel metodológico central" (Clifford, 1998: 09). Passando da conhecida "antropologia de gabinete", para a utilização da observação participante, com uma pesquisa empírica, segundo Thornton (1983) "na década de 20, o novo teórico- pesquisador de campo desenvolveu um novo e poderoso gênero científico e literário, a etnografia, uma descrição cultural sintética baseada na observação participante" (1983, apud Clifford, 1998: 27). Geertz (1978a) enfatiza o que:

Segundo a opinião dos livros- textos, praticar etnografia é estabelecer relações, selecionar informantes, transcrever textos, levantar genealogias, mapear campos, manter um diário, e assim por diante. Mas não são essas coisas, as técnicas e os procedimentos determinados, que definem o empreendimento. O que define é o tipo de esforço intelectual que ele representa: um risco elaborado para uma "descrição densa" [...] (Geertz, 1978: 04)

Diante dessa "nova forma" de pesquisa antropológica, inovações eram visivelmente notadas na feitura dos trabalhos etnográficos. Algumas mudanças ressaltadas por James Clifford (1998c) eram: primeira "a persona do pesquisador foi legitimada tanto pública quanto profissionalizante" (Idem, 28) considerando desta forma, que o pesquisador deveria viver na aldeia nativa; a segunda mudança abordava que "era tacitamente aceito que o etnógrafo de novo estilo [...] podia eficientemente “usar" as línguas nativas mesmo sem dominá-las", (Idem, 28) neste caso, deveria evitar

\footnotetext{
${ }^{8}$ Podemos utilizar a categoria utilizada por Magnani de "pedaço", onde: "A noção de pedaço, por exemplo, supõe uma referência espacial, a presença regular de seus membros e um código de reconhecimento e comunicação entre eles.". (MAGNANI, 2002, www.n-a-u.org.depertoededentro..html. Acessado em 25/03/2013).
} 
os intérpretes; a terceira estaria ligada na ênfase alocada no poder da observação, onde "o trabalho de campo bem-sucedido mobilizava a mais completa variedade de interações, mas uma distinta primazia era dada ao visual: a interpretação dependia da descrição"; (Idem, 29) a quarta relacionava-se a questão dos pesquisadores procurarem dados que os permitissem chegar mais próximo do que "buscavam"; a quinta relacionava-se diante da complexidade encontrada nas culturas, e devido o curto prazo de pesquisa, é de grande valia que" o novo etnógrafo pretendia focalizar tematicamente algumas instituições específicas" (Idem 30); por último, o" o pesquisador de campo, operando de modo intensivo, poderia, de forma plausível, traçar o perfil do que se convencionou chamar de" presente etnográfico'. (Idem, 30)

Considerando estas elucidações afirmadas por James Clifford (1998d), é de grande valia perceber os entraves encontrados em pesquisas de campo. Com a realidade de competitividade encontrada entre os mototaxistas no meio urbano de Campina Grande, essa busca "constante" por passageiros dificulta uma conversa com os mesmos. Assim, faz-se necessário colocar em prática a observação participante, que "serve como uma fórmula para o contínuo vaivém entre o “interior' e o “exterior” dos acontecimentos: de um lado, captando o sentido de ocorrências e gestos específicos, através da empatia; do outro, dá um passo atrás, para situar esses significados em contextos mais amplos" (Clifford, 1998: 33). Ainda relacionados aos meios urbanos, Magnani afirma a necessidade de recorrermos a métodos etnográficos, que nos ajudem a abarcar tais elementos:

\begin{abstract}
Assim, o que se propõe inicialmente com o método etnográfico sobre a cidade e sua dinâmica é resgatar um olhar de perto e de dentro capaz de identificar, descrever e refletir sobre aspectos excluídos da perspectiva daqueles enfoques que, para efeito de contraste, qualifiquei como de fora e de longe. (Magnani,2002, www.n-au.org.depertoededentro..html. Acessado em 25/03/2013)
\end{abstract}

Dessa forma, faz-se necessário observar de maneira assídua o cotidiano desses trabalhadores para então, "compreender"9 a sua realidade, e poder ganhar uma confiança por parte dos mesmos. Inicialmente, percorri os pontos de mototaxistas

\footnotetext{
${ }^{9}$ Para João de Pina Cabral, para que haja uma "compreensão de uma qualquer mensagem depende da sua contextualização por relação a um universo referencial que será sempre um mundo social" (Cabral, 2003: 109).
} 
encontrados no centro da cidade, observando como era realizada a cooptação dos passageiros, a forma como eles os abordavam e a quantidade de mototaxistas por ponto.

Estando no centro de Campina Grande cerca de vinte pontos de mototaxistas cadastrados na STTP, no momento fez-se necessário escolher um ponto específico para então buscar a aproximação com estes trabalhadores, este ponto se encontra na Rua: Venâncio Neiva, próximo a bancos e lojas, como pode ser visto na figura abaixo:

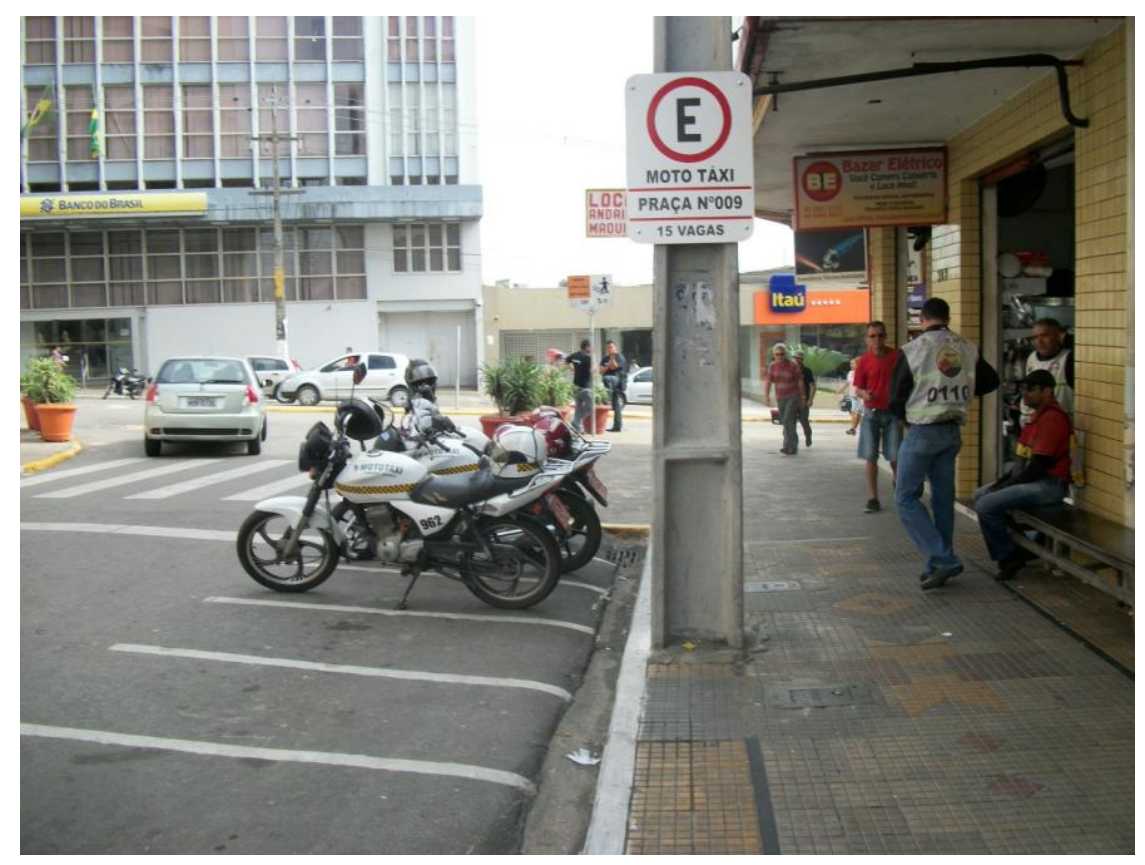

Foto 1: Rua Venâncio Neiva, Campina Grande (03/06/2013). Fotografia: Anny Timóteo

O local em que eles ficam esperando os passageiros é chamado por eles de P.A (ponto de apoio). No caso desta P.A, existem quinze mototaxistas cadastrados na STTP, onde cada um apresenta suas particularidades, tanto na forma de trabalhar, como na forma que ingressaram neste meio. A partir da escolha do ponto, passei a frequentá-lo todos os dias. Apresentando-me e falando o que pretendia fazer, passei a ser chamada por eles de "pesquisadora", dessa forma, sempre que eu chegava ao ponto, eles já reservavam um lugar no banco onde ficavam sentados, para que eu pudesse sentar próximo deles. No primeiro contato, alguns se sentiam acanhados de conversar comigo, outros falavam: “a senhora aqui de novo?", mas depois de alguns dias todos queriam manter um contato, contar uma história. Passei a chegar ao ponto por volta das 
08h00min, horário que a grande maioria deles chegava, e ficava até aproximadamente 17h30min.

Possuindo quinze mototaxistas no ponto escolhido, mas com a diferenciação dos horários de trabalho realizado por eles, dificilmente era possível encontrar todos no ponto, dessa forma, passei a ter mais contato com um grupo menor que frequentava todos os dias, praticamente no mesmo horário, assim, minhas conversas focavam um grupo de cinco mototaxistas.

Apresentando uma liberdade com relação ao horário de trabalho, a trajetória desses mototaxistas diferencia. A forma como eles organizam a questão dos passageiros é por ordem de chegada, então o mototaxista que chegar mais cedo ao ponto, será o primeiro a pegar um passageiro, e assim por diante. Como o movimento do centro da cidade começa após a abertura das lojas, por volta das 08h00min horas, alguns deles ficam em outros pontos da cidade, como por exemplo, a rodoviária no centro da cidade, a procura de alguns passageiros que chegam de cidades vizinhas. No final do dia, ocorre o mesmo processo, têm-se o exemplo de um mototaxista que após 16h: 00 min. resolve ir para o bairro da Prata, que se caracteriza por abarcar um grande número de consultórios médicos, havendo assim uma quantidade maior de passageiros, já que o movimento do centro diminui um pouco com o encerramento das atividades nos bancos.

Neste meio, existem aqueles que amam a profissão, pelo fato de sua liberdade de horário, não ter patrão, poder conhecer melhor a cidade que mora, "sempre ter um trocadinho no bolso ${ }^{10}$ " e ter contato com várias pessoas. Mas, é visto que alguns trabalhadores sentem falta de uma estabilidade que pode ser proporcionada por outro tipo de emprego. Essa insatisfação também parte da ausência de segurança presente neste trabalho, à maioria deles já sofreram algum tipo de acidente no trânsito, alguns ficando com sequelas e outros falam já terem perdido amigos. O sol e a poluição que os mesmos estão expostos diariamente deixam alguns deles insatisfeitos com o trabalho. Sem falar nos assaltos corriqueiramente que os mototaxistas vêm sofrendo, criando um ambiente de trabalho perigoso, onde a todo o momento eles estão correndo risco de vida. É neste cenário de insegurança e instabilidade que eles vêm tentando se afirmar e sobreviver. Para obter algumas informações sobre esses trabalhadores fez-se necessário criar uma interação com os mesmos, considerando que:

${ }^{10}$ Fala dos mototaxistas com relação a ter dinheiro no bolso. 
Um pesquisador capaz de uma "boa" interação com as minorias ou grupos populares será sempre um porta-voz de seus anseios e carências, logo, da sua "verdade". O critério para avaliar as pesquisas é principalmente sua capacidade de fotografar a realidade vivida. (Cardoso, 1986: 95)

Com essa interação, pôde-se notar essa insatisfação por parte de alguns mototaxistas e a "ilusão"11 daqueles que entram neste ramo. Esta "ilusão" retratada pelos mototaxistas mais antigos (apresentando mais de dez anos neste meio) e cansados com a profissão está relacionada aqueles que acabaram de entrar neste meio e é fixada na maneira pela qual estes novos mototaxistas pensam com relação a este trabalho. A ausência de patrão, e sem pressão com relação ao horário, aumentam o anseio de se tornar um deles. Estes novos, por sua vez, buscam o maior número de corridas possíveis, apresentando uma jornada de trabalho maior que oito horas diárias, chegando ao ponto de apoio às $08 \mathrm{~h} 00 \mathrm{~min}$, preferem não parar para almoçar, comendo algo rápido e sempre esticando mais no horário da noite. Além dessa diferenciação dos horários de trabalho, existem as "corridas" para bairros mais afastados do centro, que demandam um tempo maior e muitas vezes os que trabalham a mais tempo como mototaxistas preferem não ir, como um deles comentou : “o tempo que gasto indo pra lá, eu faço duas corridas aqui pra perto, não compensa ir pra longe". Ainda relacionando aos novatos, eles veem este trabalho como um víeis de "liberdade", já que podem fazer o horário de trabalho que lhes convém. Aqueles mais antigos, que estão saturados com a forma de trabalho, demonstram com mais firmeza os perigos encontrados nesse meio, alguns exemplos são as desavenças e o desrespeito que eles sofrem no trânsito. Para perceber esses nuances do dia -a- dia dos motoqueiros, fez-se necessário um olhar de "dentro" deste universo, na perspectiva de Magnani:

A simples estratégia de acompanhar um desses "indivíduos" em seus trajetos habituais revelaria um mapa de deslocamentos pontuado por contatos significativos, em contextos tão variados como o do trabalho, do lazer, das práticas religiosas, associativas etc. É neste plano que entra a perspectiva de perto e de dentro, capaz de apreender os padrões de comportamento, não de indivíduos atomizados, mas dos múltiplos, variados e heterogêneos conjuntos de atores sociais cuja vida cotidiana transcorre na paisagem da cidade e depende de seus equipamentos. (Magnani, 2002, www.n-a-u.org.depertoededentro..html. Acessado em 25/03/2013)

\footnotetext{
${ }^{11}$ Termo utilizado por mototaxistas que estão a mais tempo nesse meio para definir os que estão entrando a pouco tempo.
} 
Com esta perspectiva, acompanhando o dia- a - dia desses trabalhadores, pode-se perceber que os mototaxistas considerando a concepção de trabalho livre, já que eles fazem seu horário, para garantir o seu sustento, passam a trabalhar várias horas por dia. Mesmo sendo visto como um meio de transporte indispensável pela sua mobilidade, rapidez nos serviços prestados e um baixo custo, comparando-se aos táxis, por exemplo, os mesmos sofrem críticas pela forma de se portarem no trânsito de Campina Grande.

\section{Considerações Finais}

Com estas abordagens, podemos perceber as diversidades encontradas no meio urbano de Campina Grande. As tentativas de resistir ao desemprego faz com que homens e mulheres procurem formas de trabalho informais, ou aqueles em que não precisam comprovar um nível de escolaridade. Com a precariedade dos meios de transporte da cidade, essa categoria moto-táxi cresce de forma exorbitante, mas, o número de mototaxistas acaba sendo maior que o número de passageiros a procura deste serviço, além dos mototaxistas clandestinos que passam a apanhar passageiros que podiam ser daqueles regularizados.

Podemos perceber pontos positivos e negativos nesse "novo" segmento de trabalho. Alguns optam por adentrar nesse meio, pela "liberdade" que este emprego proporciona, já que inexiste um patrão, nem horário para começar ou terminar o expediente de trabalho. Muitos jovens vêm como uma forma de liberdade trabalhar como mototaxista, ou até como uma maneira de paquerar ${ }^{12}$ algumas passageiras. Mas é visto que essa categoria sofre críticas e desconfianças em decorrência de constantes assaltos praticados por falso mototaxista que utilizam dos artefatos dos mototaxistas cadastrados para praticarem assaltos, além desse desconforto, existe a repulsa por parte de alguns usuários do trânsito com relação a estes pilotos, que são vistos muitas vezes como irresponsáveis, agressivos e aqueles que não respeitam as leis de trânsito. Assim, podemos perceber algumas características que Marc Augé defende com relação aos meios urbanos:

\footnotetext{
${ }^{12}$ Essa caracterização partiu de relatos de jovens que trabalhavam como mototaxistas na Rocinha, RJ.
} 
Desde então, a urbanização se apresenta sob dois aspectos contraditórios, mas indissociáveis, como as duas faces de uma mesma moeda: de um lado, o mundo é uma cidade (a "metacidade virtual", de que fala Virilio), uma imensa cidade onde trabalham os mesmos arquitetos, onde se encontram as mesmas empresas do outro, a grande cidade é um mundo, onde se encontram todas as contradições e os conflitos do planeta, as consequências do fosso crescente entre os mais ricos dos ricos e os mais pobres dos pobres [...] Essa diversidade reenvia às desigualdades gritantes que traduz a organização do espaço [...] (Augé, 2010: 43).

Levando em consideração a discussão proposta à cima, podemos ver o quão é diversificado o meio urbano, no qual os mototaxistas estão inseridos. Apreendendo a realidade de alguns desses profissionais, a maioria insatisfeito com a vida que levam, podemos assim perceber quão árdua é essa profissão, a insegurança que o próprio meio de trabalho (motocicleta) proporciona é algo visível, e a instabilidade no salário é outro ponto recorrente nas afirmações destes trabalhadores. Tendo em vista estas observações, o que predomina em muitos discursos com relação a estes profissionais seriam o preconceito a instabilidade e a insegurança que este meio de trabalho proporciona, mostrando a luta diária desses trabalhadores, que buscam uma maneira de sobreviver nas desigualdades encontradas neste meio urbano.

\section{Referências}

AUGÉ, Marc. “A urbanização o mundo”. In: Por uma antropologia da mobilidade. EDUFAL: UNESP, 2010.

CARDOSO, Ruth. "As aventuras de antropólogos em campo ou como escapar das armadilhas do método" (org). In: A aventura antropológica: teoria e pesquisa. Rio de Janeiro: Paz e Terra, 1986.

CABRAL, João de Pina. 2003 "Semelhança e verossimilhança: horizontes da narrativa etnográfica”. In: Mana. Estudos de Antropologia Social, 9 (1)

CLIFFORD, J. 1998[1983]. "Sobre a Autoridade Etnográfica" e "Sobre a Alegoria Etnográfica". In: A experiência Etnográfica. Antropologia e literatura no século XX. Rio de Janeiro, UFRJ.

COMAROFF, Jean e John. 2010. “Etnografia e imaginação histórica”. In: Revista Proa, 2 (1). FONSECA, Natasha Ramos Reis da, "Sobre duas rodas: o mototáxi como uma invenção do cotidiano". Rio de Janeiro, 2005.

GEERTZ, Clifford, 1978. "Uma descrição densa: por uma teoria interpretativa da cultura" In: A interpretação das culturas. Rio de Janeiro: Zahar Editores 
HANNERZ, Uff 1997. "Fluxos, Fronteiras, Hibridos: Palavras- chave da Antropologia Transnacional”. In: Mana. Estudos de Antropologia Social, 3 (1).

LUNA, Jucelino Pereira. $O$ trabalho reconfigurado e a nova condição do trabalho informal $e$ precário: a saga dos trabalhadores de moto-táxi em Campina Grande. Campina Grande/PB, UFCG, Unidade Acadêmica de Ciências Sociais. 213 pg. Tese de Doutorado em Ciências Sociais.

MAGNANI, Jose Guilherme. De Perto e de Dentro: Notas para uma Etnografia Urbana. NAU: Núcleo de Antropologia Urbana da USP. Disponível em http://www.n-au.org.depertoededentro..html. Capturado em 13/08/2010.

PARK, Ezra. “A cidade: sugestões para a investigação do comportamento humano no meio urbano” In: O Fenômeno Urbano, Rio de Janeiro: Ed Zahar, 1973. [26-67].

WIRTH, Louis. "O urbanismo como modo de vida". In: O fenômeno urbano, Rio de Janeiro: Ed Zahar, 1973.

Recebido em: 15/08/2013

Aprovado em: 22/08/2013 